\title{
Species diversity of the family lecithoceridae (lepidoptera: gelechioidea) in the world
}

Keywords: Species diversity, lecithoceridae, zoogeographical region

\section{Introduction}

The biodiversity is a basic element of ecosystem functions and the natural capital for our life and economic property. Thus, the biodiversity impoverishment is not only the loss of species but also the destruction of our life-support system and natural capital assets. For the sustainable use of the biodiversity, the discovery of new living organisms on our planet is important and valuable as much as the preservation of them, and is another urgent task because it is now in a "CRISIS", lacking experts and funds. The real facing problem is that the number of well-trained taxonomists is decreasing in the worldwide at a time when demanding taxonomy, a basic science, is increasing, following advanced technology to be used. Since Linneaus (1758) named 4,162species of living organisms, 1.9 million species have been identified and named. It is less than $20-35 \%$ of $5-10$ million species estimated commonly on our planet. By the present prevailing tendency to discover unknown species, it would take another 1,400years to complete the documentation of all global organisms. To overcome the taxonomic impediment and speed up the discovering process for new taxa before too late, the initial step is establish international networks among countries and/or specialists collaborating together.

The family Lecithoceridae (Lepidoptera, Gelechioidea) is a poorly known group of micro lepidoptera, although it is one of highly diversified groups, and estimated more than 1,260 known species worldwide. However, the taxonomic study for the family has been ignored and neglected due to less or no economic importance. The larvae usually feed on non living material and organisms. The total species estimated from the family could be over at least 3-4 times than the present known species number, because the most of the subtropical and tropical areas including the Southern Asia and Africa have not been explored. Adult moths are normally nocturnal activity although some of the brightly colored species, e.g., Issikiopteryx and Crocanthes species may be diurnal. The family is well defined by the apomorphies, having the antennae being longer than the forewing and the mesial process of gnathos being downturned. Gozmány (1978) suggested that these morphological characters support to the Lecithoceridae as a monophyletic group, distinguished from other related families. Since the representative genus Lecithocera Herrich-Shäffer, 1853 was established and belonged in the family Oecophoridae, the taxonomic status of the family had not been well defined due to a variety of different opinions for its rank, placing it in Gelechiidae (Meyrick, 1925), ${ }^{1-3}$ or in the Timyridae by Clarke ${ }^{4}$ which was synonymized with Lecithoceridae. According to a recent parsimony analysis by the combined morphological and molecular data, the family Lecithoceridae is classified in a sister of Autostichiidae or Autostichiidae+Xyloryctidae. ${ }^{5,6}$ The family Lecithoceridae was divided with three subfamilies by Gozmány (1978): Ceuthomadarinae Gozmány, Lecithocerinae Marchand, and Torodorinae Gozmány, however, a new subfamily Crocanthinae has been recently proposed by Park $^{7}$ based on the genus Crocanthes Meyrick. The Lecithocerinae is characterized by the presence of a bridge-like structure connecting the
Volume 2 Issue I - 2018

\author{
Kyu-Tek Park \\ Incheon National University, South Korea
}

Correspondence: Kyu-Tek Park, Incheon National University, Incheon-220I2, South Korea, Email ktpark02@gmail.com

Received: December 03, 2017| Published: January 17, 2018

tegumen and the valval costa of the male genitalia, the Torodorinae is distinguished from Lecithocerinae by the bridge-like structure in the valva not developed and with thorn-like uncus in the male genitalia, and the Crocanthinae represents synapomorphies presenting more relatively bright-colored wings, often the hindwing with the similar markings as those of forewing, and the gnathos absent or remarkably reduced in the male genitalia.

More than 1,260 species have been enumerated in the five zoogeographical regions (Table 1); Oriental, Palaearctic, Ethiopian, Australian, and Oceanian region, except Neotropical Neoarctic regions (with few exceptions). In the all known species worldwide, there are more than 840 species ( $>66 \%$ of all known species) in the Oriental Region, following the Oceanian Region with 158 known species $(>12 \%)$, and then less than 130 species $(<10 \%)$ in the Palaearctic Region.

Table I The number of the known species in the world

\begin{tabular}{lllllll}
\hline & OR & PA & ET & AU & ON & Subtotal \\
\hline Ceuthomadarinae & $\mathrm{I}$ & 3 & 4 & - & - & 8 \\
Lecithocerinae & $>500$ & 75 & 69 & 37 & 91 & $>770$ \\
Torodorinae & $>330$ & 50 & 19 & 2 & 2 & $>400$ \\
Crocanthinae & 3 & - & - & 17 & 65 & 85 \\
subtotal & $>840$ & $>120$ & $>90$ & 55 & 158 & $>1,260$
\end{tabular}

OR, Oriental Region; PA, Palaearctic Region; ET, Ethiopian Region; AU, Australian Region; ON, Oceanian Region

A recent study ${ }^{8}$ has noted that Australian and Oceanian region are geographically very close to each other but the species composition of Lecithoceridae in both regions quite differs each other. For example, the Crocanthinae have 65 species known in the Oceanian Region among the total of 85 known species in both regions, and 17 species in the Australian Region with only two species overlapped in both regions. It means that more than $95 \%$ of the species are endemic in each region. Gielis ${ }^{9}$ also reported a similar result from his faunal study of the family Pterophoridae in New Guinea. These results might inadequately reflect the actual diversity of species in the regions because of the limited samplings. Nevertheless, these data could support an evidence that the island of New Guinea was geographically 
formed in different plates and times from the Australian region, and also support the revised division of the zoogeographical regions of the world by Holt et al. ${ }^{10}$ updated Wallace's zoogeographic regions, separating the Oceanian Region from the Australian Region.

\section{Conclusion}

On the other hand, our knowledge of the biodiversity on our planet is quite limited because we are still neglecting and ignoring an important biological heritage in many unexplored areas such as Africa, the Eastsouthern Asia including South Pacific islands. As shown the case of Lecithoceridae, the recent study of Afro-lecithocerids (in mans., 2018) was possible by the contribution of materials from various museums and colleagues, sending to me. From those specimens, I found that most of species have never been recognized and belong to unknown and different genera, comparing to species and genera from the Oriental and Oceanian regions. Therefore, they should be reconsidered for their generic groups. The major diagnostic character of the family having the longer antenna than forewing is not consistent from some of these species, even though they are no doubt belonging to Lecithoceridae by other morphological characters including the genitalia. From these observations, I have doubtful questions about the phylogenetic diagrams on the super family Gelechioidea, based on molecular works by various authors including Sohn et al. ${ }^{6}$ that could neglect and miss some Afrotropical elements. Our taxonomical finding and knowledge on the fauna of microlepidoptera in the world seems to have only a piece of the actual existence so far.

\section{Acknowledgements}

None.

\section{Conflict of interest}

Author declares there is no conflict of interest in publishing the article.

\section{References}

1. Diakonoff, A. Microlepidoptera of Philippine Islands. Bulletin US National Museum. 1967;257:125-147.

2. Janse AJT. Gelechiidae. The moths of South Africa, Pretoria, South Africa; 1954;5(4):332-349, 362-363, 366-370, 377-384.

3. Hodges RW. Gelechoidea, Cosmopterigidae. In: Dominick RB, Ferguson D, editors. The moths of America North of Mexico. Fasc 6.1. EW Clasyy Limited and The Wedge Entomomological Research Foundation, 1978. p. 166.

4. Clarke JFG. Catalogue of the type specimens of Microlepidoptera in the British Museum (Natural History) described by Edward Meyrick. Trustees of the British Museum, London, UK; 1965;5:255.

5. Heikkilä M, Mutanen M, Kekonen M, et al. Morphology reinforces proposed molecular phylogenetic affinities: a revised classification for Gelechioidea (Lepidoptera). Cladistics. 2014;30(6):563-589.

6. Sohn JC, Regier JC, Mitter C, et al. Phylogeny and feeding trait evolution of the mega-diverse Gelechioidea (Lepidoptera: Obtectomera): new insight from 19 nuclear genes. Systematic Entomology. 2016;14(1):112-132.

7. Park KT. A new subfamily Crocanthinae based on the genus Crocanthes Meyrick and its related genera, with a world catalog of the subfamily (Lepidoptera, Lecithoceridae). Journal of Asia-Pacific Biodiversity. 2015;8(4):251-286.

8. Park KT, Cho SW, Bae YS. Review of Lecithoceridae (Lepidoptera: Gelechioidea) in the Oceanian Region, with description of a new species and a checklist of the family. Zootaxa. 2017;4147(2):143-161.

9. Gielis C. Review of the Pterophoridae from New Guinea, with descriptions of eight new species (Lepidoptera). Zoologische Mededelingen. 1990;77(21):349-391.

10. Holt BG, Lessard JP, Borregaard MK, et al. An update of Wallace's zoogeographic regions of the world. Science. 2013;339(6115):74-78. 